Research Article

\title{
Study on Stress Relief of Hard Roof Based on Presplitting and Deep Hole Blasting
}

\author{
Peng Gong $\mathbb{D})^{1,2}$ Yongheng Chen $\mathbb{D}^{2},{ }^{2}$ Zhanguo $\mathrm{Ma}^{1,2}$ and Shixing Cheng $\mathbb{D}^{1}$ \\ ${ }^{1}$ State Key Laboratory for Geomechanics and Deep Underground Engineering, China University of Mining and Technology, \\ Xuzhou 221116, Jiangsu, China \\ ${ }^{2}$ School of Mechanics and Civil Engineering, China University of Mining and Technology, Xuzhou 221116, Jiangsu, China
}

Correspondence should be addressed to Peng Gong; gongpeng1220@126.com

Received 23 June 2020; Revised 7 September 2020; Accepted 23 September 2020; Published 28 October 2020

Academic Editor: Bisheng Wu

Copyright (C) 2020 Peng Gong et al. This is an open access article distributed under the Creative Commons Attribution License, which permits unrestricted use, distribution, and reproduction in any medium, provided the original work is properly cited.

\begin{abstract}
For the problem that the hard roof causes wider end-mining coal pillar, and the roadway is greatly affected by mining, this paper took Shanxi Luning Coal Mine as the engineering background; based on the stress distribution characteristics of the coal pillar, the calculation method of the limit end-mining coal pillar size was given; considering the formation conditions and transmission forms of the advanced abutment stress, a method combining presplitting and deep hole blasting was proposed to weaken the advanced abutment stress. The numerical simulation was used to analyze the stress distribution of coal pillars, which was verified by on-site industrial tests. The results showed that the presplitting can achieve the blocking of stress. The closer it is to the peak of the abutment stress, the better the blocking effect. Deep hole blasting can weaken the source of the advanced abutment stress and reduce the peak of abutment stress. With the combination of the two blasting methods, the end-mining coal pillar size of Luning Coal Mine can be reduced to $60 \mathrm{~m}$. The method combining presplitting and deep hole blasting can effectively reduce the endmining coal pillar size and reduce the impact of mining on the deformation of the dip roadway.
\end{abstract}

\section{Introduction}

The hard roof suspension structure is not easy to collapse, which will lead to an increase in the peak value of the advanced abutment stress and the effect range $[1,2]$. When the mining panel is close to the dip roadway, if the size of the reserved coal pillar is insufficient, the energy released by the roof fracture and the mining stress will have a serious impact on the remote roadway [3-5]. Therefore, the roads are often protected by increasing the size of the coal pillars, resulting in waste of coal resources.

The pressure relief methods for hard roofs are mainly divided into three types: hydraulic fracturing, water injection weakening, and physical blasting. The principle is to reduce the integrity of the rock mass by weakening the load-carrying capacity or blocking the transmission of the internal force of the rock layer; from the perspective of reducing the integrity of the rock mass, people initially used water injection to change the rock properties to weaken it, but this method is not suitable for hard roofs with dense structures; the current more mature method is physical blasting; artificial cracks are formed by blasting and interpenetrate with the original cracks under the pressure of the mine so that the roof is easy to collapse and the stress concentration in front of the coal wall is reduced. Blasting pressure relief has a lot of research in theory and practical application; Xia et al. [6] used shallow hole blasting to reduce the roof pressure in front of the mining panel and then combine grouting reinforcement technology to improve the stability of roadway surrounding rock; Zuo et al. [7] used theory, and the method of numerical simulation was used to study the evolution behavior of the stress field induced by deep hole blasting. Zhou et al. [8] analyzed the internal dynamic response of coal pillars during the mining process using PFC software. In recent years, there have also been studies using hydraulic fracturing techniques to increase the degree of rock fragmentation. 
The main way to block the transmission of stress in the rock layer is to create a fracture surface inside the rock layer, weaken the bearing stress generated by the suspended ceiling structure, and change the distribution of the bearing stress field from the source. At present, the technology is widely used in the gob-side entry retaining. For example, Liu et al. [9] and Chen et al. [10] have studied the roof structure and pressure relief effect in the roadway along the gob. Hu [11] established a mechanical model of gob-side entry retaining related to the strength of the support and calculated a reasonable presplitting height; Huang et al. [12] used directional hydraulic fracturing to cut the outer roof of the coal pillar to achieve the purpose of protecting the roadway. In recent years, some people have used directional presplitting technology to control the advanced abutment stress and cyclic pressure. Yang et al. [13, 14] respectively adopted directional hydraulic fracturing technology and directional energy gathering blasting technology to presplit the front roof of the mining panel, thereby shortening the cyclic pressure step to reduce the energy accumulated in front of the coal wall.

It can be seen from previous studies that although hydraulic pressure has been applied in the field as an emerging technology to control the advanced abutment stress, the fracturing process is not easy to control and is seriously affected by the original cracks in the rock mass. The development of physical blasting technology has been very mature, but it mostly stays in the application research of a single method and fails to combine the advantages of multiple blasting methods to achieve efficient control of the pressure field. In this paper, based on the actual background of the project, considering the stress distribution inside the coal pillar and the advantages of various blasting methods, this paper proposes a pressure relief method combining presplitting blasting and deep hole blasting to control the advanced abutment stress through numerical simulation and industrial experiments to study the effect of pressure relief.

\section{Research on Coal Pillar Stress Distribution and Roadway Stability}

2.1. Coal Pillar Stress Distribution and Size Calculation. Reasonable width of the end-mining coal pillar should ensure the stability of the roadway surrounding rock while reducing the size as much as possible to improve resource utilization. The redistribution of initial rock stress field was caused by roadway excavation. As shown in Figure 1, the broken area I, plastic area II, and elastic area III are formed in turn along the roadway. The broken area and plastic area can be collectively called the limit equilibrium area. In the initial mining period, the mining panel is far away from the roadway, and the advanced abutment stress of the mining panel is also distributed in 3 areas, and the original rock stress zone IV still exists between the mining panel and roadway. With the advancement of the mining panel, the influence range of the advanced abutment stress continues to move forward, and the original rock stress zone gradually decreases. According to rock mechanics, $5 \%$ of the original rock stress is selected as the boundary between the elastic zone and the original rock stress field. When the elastic area of the abutment stress field overlaps with the surrounding rock stress area of the roadway, the roadway will gradually become unstable and be destroyed. Therefore, the width of the limit end-mining coal pillar is the sum of the range I and II of the surrounding rock stress area of the roadway and the area I, II, and III of the advanced abutment stress zone.

The range of the advanced abutment stress zone is the sum of the width of the limit equilibrium zone $x_{1}$ and the width of the elastic zone $x_{2} . x_{1}$, and $x_{2}$ can be calculated by the following [15] equations:

$$
\begin{gathered}
x_{1}=\frac{M(1-\sin \varphi)}{2 f(1+\sin \varphi)} \ln \left\{\frac{K \gamma H(1-\sin \varphi)}{\tau_{0} \cot \varphi(1+\sin \varphi)}\right\}, \\
x_{2}=\frac{M \beta}{2 f} \ln \frac{K}{1.05},
\end{gathered}
$$

where $x_{1}$ is the width of the plastic zone; $x_{2}$ is the width of the elastic zone; $M$ is the thickness of the coal seam, $4.0 \mathrm{~m}$; $f$ is the friction angle, $31^{\circ} ; f$ is the friction factor between the coal seam and the roof and floor, 0.16 ; $\tau_{0}$ is the cohesion, $0.6 \mathrm{MPa}$; $\mathrm{H}$ is the coal seam depth, $500 \mathrm{~m} ; \gamma$ is the average bulk density of the overburden rock, $25 \mathrm{kN} / \mathrm{m}^{3}$; $\mathrm{K}$ is the maximum stress concentration factor, $3.0 ; \beta$ is the lateral pressure coefficient, 2.0 .

For the surrounding rock stress field of rectangular roadway, in the absence of structural stress, as shown in Figure 2, it should be equivalent to a circular roadway with the circumscribed circle of the roadway as the cross-section. Then, use the method of elastic-plastic limit equilibrium theory and assign a certain correction coefficient to calculate. The radius $\mathrm{Rb}$ of the limit equilibrium zone of the surrounding rock of the roadway can be obtained by the following equation:

$$
R_{b}=\eta R_{0}\left\{\left[\frac{(p+c \cdot \operatorname{ctg} \varphi)(1-\sin \varphi)}{c \cdot \operatorname{ctg} \varphi}\right]^{((1-\sin \varphi) / 2 \sin \varphi)}-1\right\},
$$

where $p$ is the original rock pressure; $\mathrm{R}_{0}$ is the circumscribed circle radius of the roadway; $c$ is the cohesive force; $f$ is the friction angle in the coal body; $\eta$ is the correction coefficient, 0.8 .

Taking the above parameters into equations (1)-(3), $x_{1}=18.6 \mathrm{~m}, x_{2}=65.3 \mathrm{~m}$, and $\mathrm{Rb}=2.6 \mathrm{~m}$, so the theoretical minimum width of the end-mining coal pillar is $L=x_{1}+x_{2}+\mathrm{Rb}=86.5 \mathrm{~m}$.

2.2. Effect of Advanced Abutment Stress on Roadway. The main roof has the characteristic of transmitting horizontal force in the direction of propulsion, which has a significant impact on the pressure of the stope. The harder the main roof, the more the weight of the overlying strata will be transferred to the surrounding rock mass, resulting in an increase in the range of the advanced abutment stress field. Therefore, the hard main roof is not only the source of the advanced abutment stress but also the main transmission 


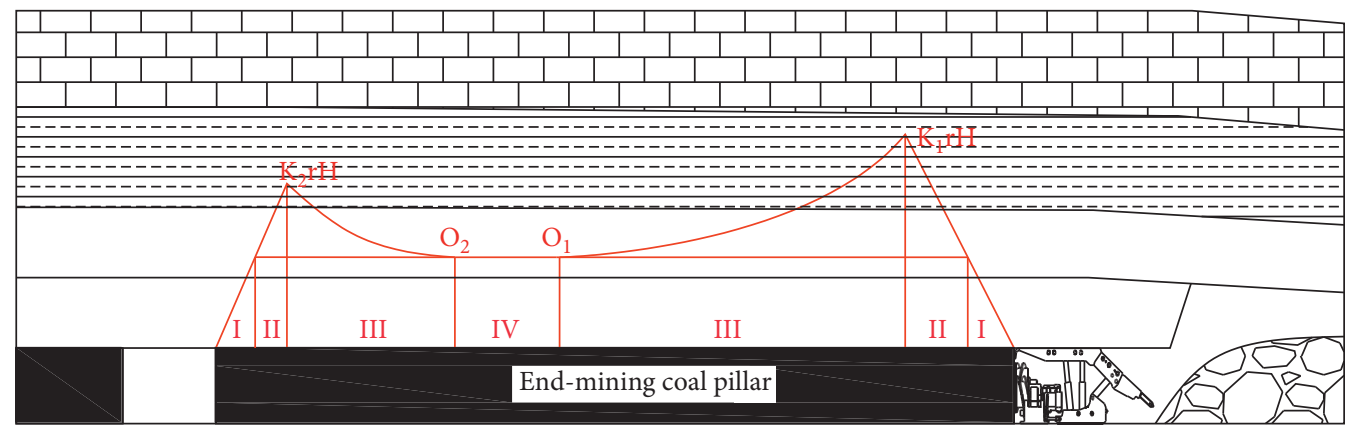

FIGURE 1: Stress distribution of the end-mining coal pillar.

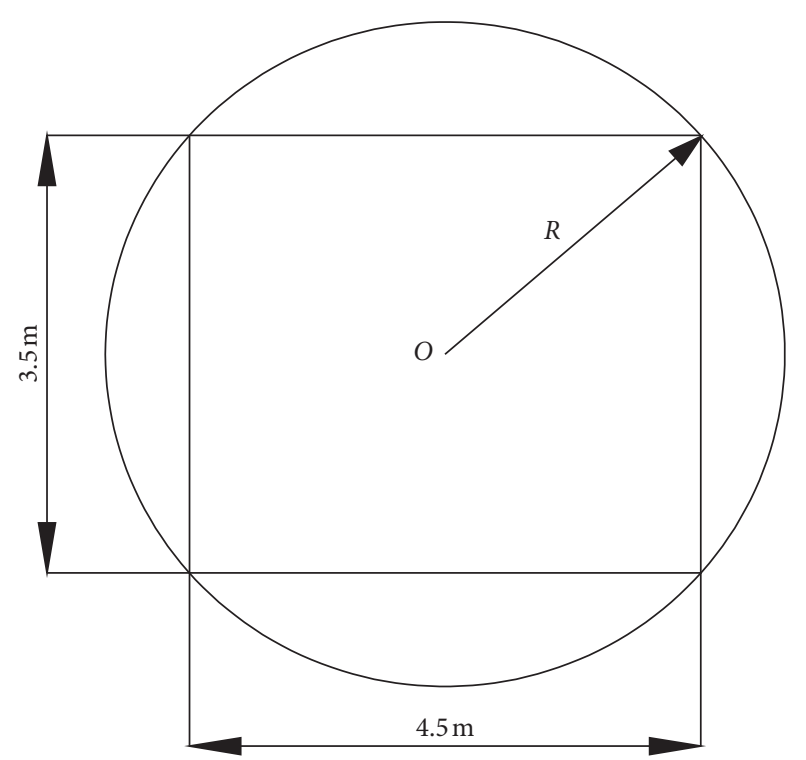

FIGURE 2: Equivalent roadway profile.

path of the abutment stress. As shown in Figure 3, based on the above two characteristics of the main roof, a stress blocking blasting pressure relief technology is proposed. First, the main roof is presplitted to block the propagation of stress. Then, reduce the roof integrity through advanced deep hole blasting. On the one hand, the internal stress will be transferred to the deep part due to the increased rock fracture. On the other hand, after the mining panel has been mined, the broken roof will collapse directly under the pressure of the overlying rock layer and will not produce a suspended roof structure, weakening the advanced abutment stress from the source. Through this combination of "prevention and treatment," the size of coal pillars and the effect of the advanced abutment stress on the stability of the surrounding rock are reduced.

\section{Mechanism of Stress Blocking and Relief}

3.1. Stress Blocking with Presplitting. The presplitting is based on the directional energy gathering blasting technology [16-18] so that the detonation product forms a super-high pressure and density shaped jet along the dire. As shown in Figure 4, the energy gathering hole is formed by drilling holes on both sides of the PVC pipe. The shaped jet penetrates and tears in a predetermined direction around the explosion hole to form an initial guide crack, which provides accurate orientation for the further effect of blasting stress wave and detonation gas, as well as the directional expansion of cracks, thereby forming a fracture surface and destroying the integrity of the roof. At present, this method is mostly used to presplit the roof above the roadway, the side roof of the gob collapses under the pressure of overburden to protect the roadway. Based on this idea of cutting off the stress transmission path, it is possible to achieve the blocking of the advanced abutment stress transmission in the roof.

During the coal seam mining, the roadway is mainly affected by two kinds of stress, namely, the redistribution of static stress after mining and the dynamic load caused by other factors such as rock fracture. The advanced presplitting will form a fault-like loosening and weakening zone around the blast hole, which will block the transmission of stress in the rock layer. (1) Blocking the transmission of static load: the macro performance of presplitting is the formation of crack surface; the contact area of the rock mass on both sides of the crack is greatly reduced, and the joint force is lost at the crack so that the ability of the roof to transmit force is weakened, and there is no ability to resist bending, shearing, and tensile. At the same time, the degree of loosening and weakening under the action of abutment pressure is increased, and the strength is further reduced. (2) Weakening the propagation of stress waves: dynamic loads such as rock fracture, collapse, and blasting propagate in the rock body in the form of stress waves. When stress waves encounter weak interfaces such as fissures caused by blasting on the transmission path, wave projection and reflection will occur, which will weaken the transmission of dynamic loads in the rock layer. Therefore, the advanced presplit blasting will block the advanced stress of the stope from the two aspects of dynamic and static loading.

3.2. Attenuation of Stress in Blasting Crack Zone. In order to study the blocking effect of the blasting fracture zone on the stress wave, the stress wave generated in the stope can be simplified as a plane wave, because the longitudinal wave velocity is much greater than the shear wave velocity, and the blasting fracture zone is perpendicularly incident. Therefore, the blocking of the dynamic load is regarded as the attenuation of the vertical stress wave incident on the 


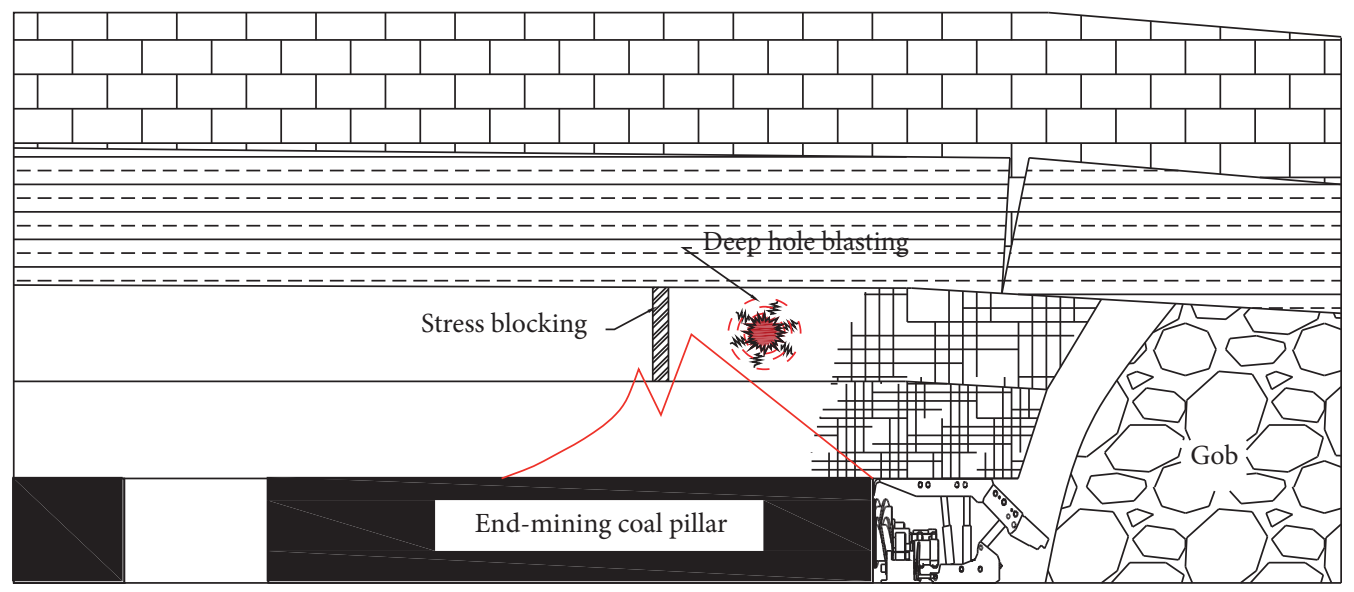

FIGURE 3: Schematic diagram of stress blocking and blasting relief.

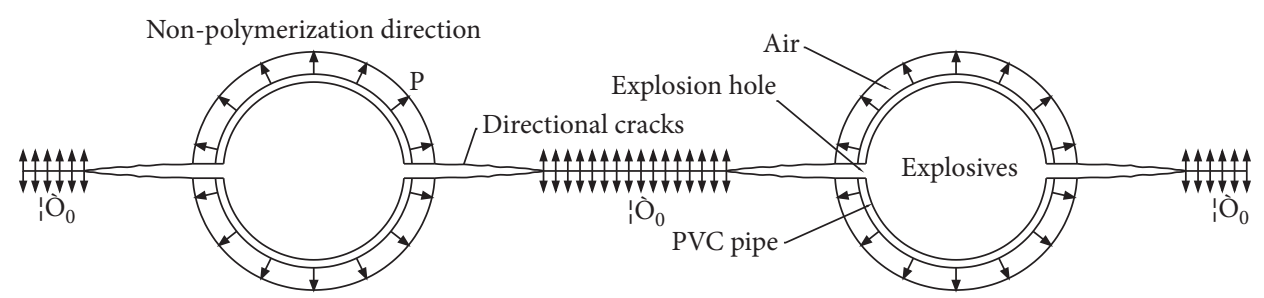

FIGURE 4: Directional energy gathering blasting.

multilayer medium. As shown in Figure 5, $\sigma_{0}$ is the initial peak stress value of the incident layer of the stress wave, and $\sigma_{\max }$ is the peak stress value after passing through the $n$ layer medium. The peak stress $\sigma_{\max }$ after $n$-layer medium can be obtained from [19] the following equation:

$$
\sigma_{\max }=2^{n} \prod_{k=0}^{n-1} \frac{\rho_{n+1} v_{n+1}\left(\sum_{k=1}^{n} d_{k}\right)^{\alpha_{n+1}}}{\left(\rho_{n} v_{n}+\rho_{n+1} v_{n+1}\right)\left(\sum_{k=1}^{n+1} d_{k}\right)^{\alpha_{n+1}}} \sigma_{0}
$$

where $\rho$ is the density of the medium; $v$ is the wave velocity of the wave propagating in the medium; $d$ is the thickness of the medium; $\alpha$ is the attenuation coefficient.

It can be known from the wave theory that when a wave is transmitted from a medium with a small wave impedance into a medium with a high wave impedance, the peak value of the wave is enhanced, and vice versa. A large number of cracks around the blast hole will cause multiple reflections of the stress wave to increase the propagation distance, and the attenuation of the stress wave will increase with the increase of the propagation distance. In addition, the redistribution of the medium state due to the work of the stress wave on the broken rock mass around the blast hole will also consume wave energy. When the stress wave propagation distance is the same, the more media layers passing through, the richer the media properties, and the faster the stress wave decay, so the blast fracture zone can effectively attenuate the stress wave generated in the rock layer.

\section{Establishment of Numerical Simulation Model}

4.1. Model Parameters and Boundary Condition. Using the numerical simulation software Fast Lagrangian Analysis of Continua in 3 Dimensions (FLAC3D) to build a numerical calculation model with the 22115 mining panel of Luning Coal Mine as the research object. As shown in Figure 6, the dimensions of the model were $392 \mathrm{~m} \times 373 \times \mathrm{m} \times 93 \mathrm{~m}$, including one mining panel and three dip roadways. Boundary conditions limit the horizontal displacement of the four sides, fixed constraints are applied at the bottom, and the top is set as a free surface. The vertical rock stress is applied at the top of the model to simulate the weight of the overburden, and based on field tests, lateral pressure is applied to the four sides of the model with a coefficient of 1.5. The calculation uses the Mohr-Coulomb model, and the physical and mechanical parameters of each rock layer are measured by on-site sampling and laboratory tests, as shown in Table 1.

The simulation involves deep hole blasting and stress wave transfer research. It is necessary to set up matching dynamic calculation conditions. For FLAC3D dynamic calculation, three aspects must be considered: dynamic load and boundary conditions, mechanical damping, and wave propagation in the model. When an explosion occurs in the rock and soil body, a blasting compression wave will first produce a compaction effect on the inner wall of the blast hole. The compression wave attenuates sharply after reaching the peak and rebounds after the load disappears. 


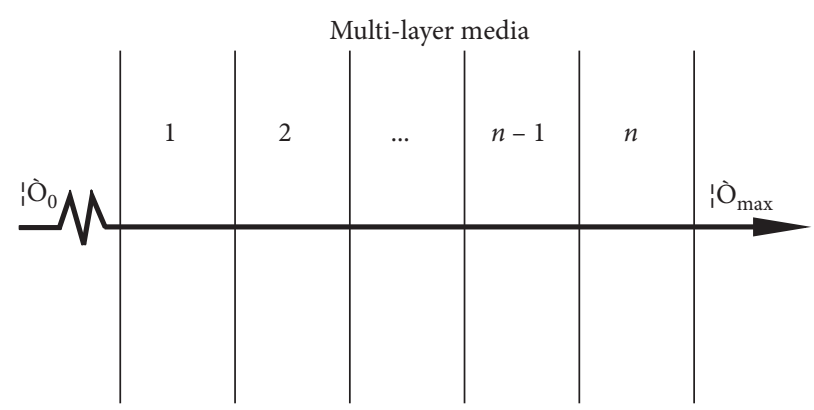

FIGURE 5: Normal transmission model of the stress wave in multilayer medium.

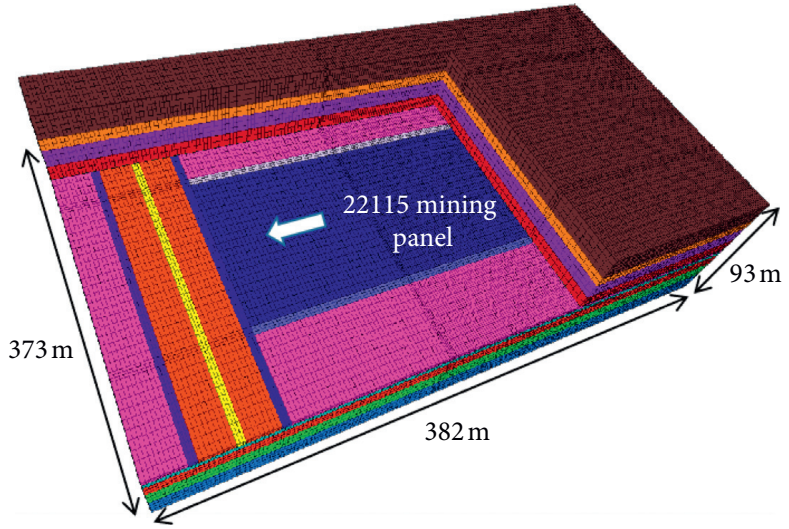

Figure 6: Overall view of the numerical simulation model.

TABLE 1: Main rock model parameters.

\begin{tabular}{lccccccc}
\hline Group name & Lithology & Bulk $(\mathrm{GPa})$ & Shear $(\mathrm{GPa})$ & Cohension $(\mathrm{MPa})$ & Friction $\left(^{\circ}\right)$ & Tension $(\mathrm{MPa})$ & Density $\left(\mathrm{kg} / \mathrm{m}^{3}\right)$ \\
\hline Main roof & Sandstone & 6.11 & 3.15 & 3.6 & 32 & 2.95 & 2600 \\
Immediate roof & Sandy mudstone & 5.61 & 3.97 & 3 & 31 & 3.33 & 2577 \\
False roof & Carbon mudstone & 3.03 & 1.32 & 1 & 23 & 1.3 & 1368 \\
Coal seam & 2\# coal & 3.03 & 1.32 & 23 & 32 & 3.5 & 1368 \\
Immediate floor & Mudstone & 9.53 & 5.17 & 3.8 & 38 & 6.06 \\
Main immediate & Siltstone & 1.01 & 6.05 & 3 & & 2624 \\
\hline
\end{tabular}

Therefore, the triangle wave with loading and unloading process can be used as the power source in the calculation [20]; the dynamic loading equation is shown in equation (5), where the total time course is $0.06 \mathrm{~s}$, and the loading section lasts $0.01 \mathrm{~s}$, unloading the segment lasts $0.05 \mathrm{~s}$, the peak load is $20 \mathrm{MPa}$, and the dynamic load and curve are shown in Figure 7.

$$
\begin{cases}A(\tau)=\frac{A}{t_{0}} \cdot \tau, & 0 \leq \tau<t_{0}, \\ A(\tau)=A-\frac{A}{t_{1}-t_{0}} \cdot\left(\tau-t_{0}\right), & t_{0} \leq \tau<t_{1}, \\ A(\tau)=0, & t \geq t_{1},\end{cases}
$$

where $t_{0}$ is the loading time; $t_{1}$ is the unloading time; $\tau$ is the time variable; $A$ is the peak load.
The damping of rock and soil mainly comes from internal friction and a large number of joint surfaces. The damping mode determines the form of dynamic load attenuation. The FLAC3D dynamic calculation module provides three damping modes, of which Rayleigh damping itself is frequency-dependent, but the frequency-independent characteristics of the rock and soil body can be obtained within a certain range by adjusting appropriate parameters. The parameters of Rayleigh damping include the minimum critical damping ratio $\varepsilon$ min and the minimum center frequency $\omega_{\text {min }}$. For geotechnical materials, the critical damping ratio generally ranges from $2 \%$ to $5 \%$. In this paper, $\varepsilon_{\text {min }}=0.05$ is directly adopted; the center frequency of the damping can be simplified to the natural frequency $f$ of the model instead. The natural frequency can set the model to elastic constitutive and apply gravity without solving damping to solve a certain number of steps to make the model oscillate. The response of key nodes in the model determines the size of the natural frequency. As shown in 


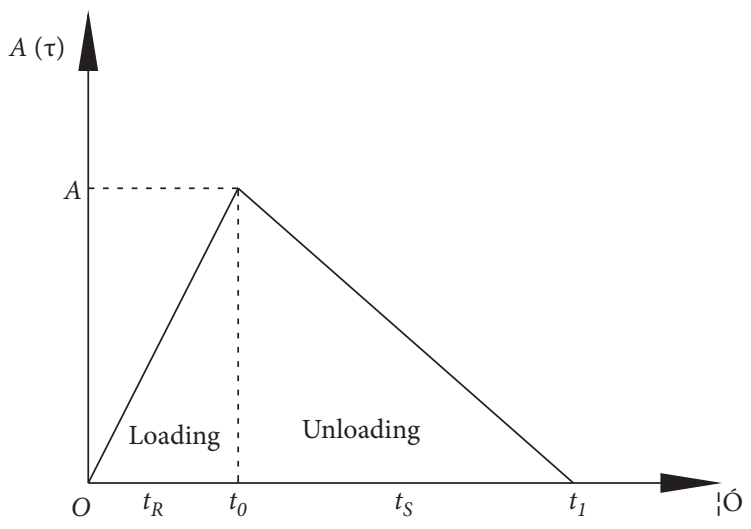

Figure 7: Dynamic load curve.

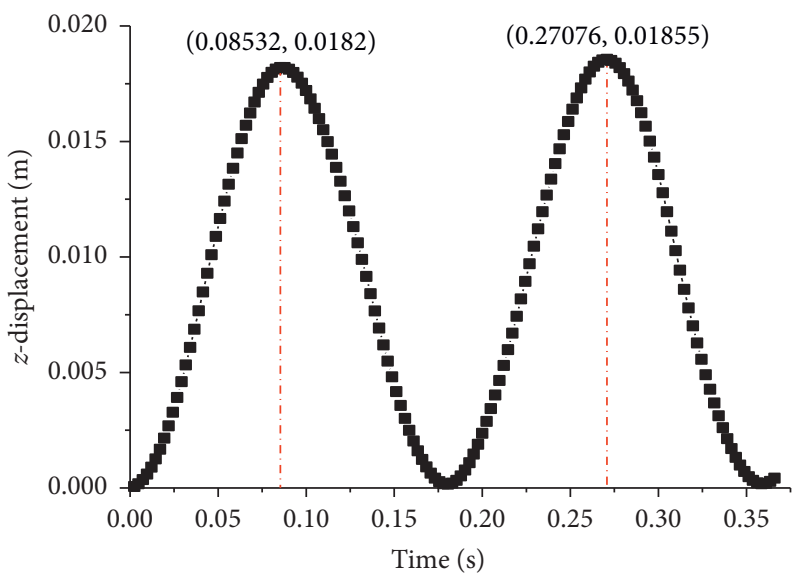

FIGURE 8: Overall view of the numerical simulation model.

TABle 2: Dynamic parameters.

\begin{tabular}{lllll}
\hline Peak load $(\mathrm{MPa})$ & Loading time $t_{\mathrm{R}}(\mathrm{s})$ & Unloading time $t_{\mathrm{S}}(\mathrm{s})$ & Minimum critical damping ratio & Minimum center frequency $(\mathrm{Hz})$
\end{tabular} 20 0.01 0.05 0.05 5.12

Figure 8, the two adjacent peaks of the displacement timehistory curve taken from vibration are a vibration period $T$, and the minimum center frequency can be obtained from equation (6) as $\omega_{\min }=5.12 \mathrm{~Hz}$. The dynamic load parameters required for the simulation are shown in Table 2 .

$$
\omega_{\min } \approx f=\frac{1}{T}
$$

where $\omega_{\min }$ is the minimum center frequency; $f$ is the natural frequency; $T$ is the vibration period.

In the calculation, the dynamic load is applied to the internal nodes of the model, and only the application of the viscous boundary can effectively reduce the reflection effect generated by the boundary. In addition, the size of the grid in dynamic calculation is closely related to the dynamic load frequency, and the frequency of the input wave and the wave velocity characteristics of the system both affect the numerical accuracy of the wave transmission. Therefore, the grid space element size $\Delta L$ must be less than about one-tenth to one-eighth of the wavelength associated with the highest frequency $f$ component of the input wave, as in equation (7). The application of the dynamic load and the determination of the grid size in the entire process are completed by the software built-in programming language fish, and in order to increase the calculation speed, a dynamic multistep calculation mode is adopted.

$$
\Delta L \leq \lambda(0.1 \sim 0.125),
$$

where $\Delta L$ is the grid space element size; $\lambda$ is the wavelength.

4.2. Simulation Scheme. The focus of this study is the blocking of stress transmission by directional presplit blasting and the effect of deep hole blasting on weakening the advanced abutment stress. With the combination of the two methods, the purpose of shortening the range of the advanced abutment stress field is achieved. The simulation is performed by the following steps: (1) firstly, coal mining is 
carried out in the conventional way, and the limit coal pillar size is determined based on the advanced abutment stress range, based on the coal pillar size determination principle given above. (2) Presplitting at different horizontal distances of the advancing mining panel, according to different stress blocking effects give the best presplitting position. (3) After determining the presplitting position, deep hole blasting dynamic load is applied to study the pressure relief effect under the combination of the two methods.

\subsection{Effect of Blasting on Coal Pillar Stress Field Distribution}

4.3.1. Determination of Coal Pillar Size. It can be seen from Figure 9 that when the mining panel is far away from the roadway, the roadway is not disturbed, and the original rock stress area exists in the coal pillar stress field. The range of the advanced abutment stress field is about $80 \mathrm{~m}$, and the peak stress is about $22 \mathrm{MPa}$. The stress field of the roadway surrounding rock is about $30 \mathrm{~m}$, and the peak stress is about $16 \mathrm{MPa}$. The advanced abutment stress field advances with the mining of the mining panel. When the coal pillar width is reduced to $115 \mathrm{~m}$, the original rock stress area gradually disappears, and the two stress fields elastic areas begin to superimpose each other, and the stress value is the result of linear superposition. When the size of the coal pillar is reduced to $85 \mathrm{~m}$, the advanced abutment stress field reaches the disturbance boundary of the surrounding rock stress field of the roadway. As the size of the coal pillar continues to decrease, the degree of disturbance in the roadway intensifies, causing the peak value of the surrounding rock stress field to increase rapidly, and the roadway gradually becomes unstable. It can be seen that without taking any measures, the end-mining coal pillar size is about $80-85 \mathrm{~m}$.

4.3.2. Stress Blocking Effect Analysis. In order to study the influence of the presplitting blasting position on the stress blocking effect, presplitting was carried out at the horizontal distances of $20 \mathrm{~m}, 35 \mathrm{~m}, 50 \mathrm{~m}$, and $65 \mathrm{~m}$ from the mining panel, respectively, to simulate the redistribution state of the advanced abutment stress field after directional presplitting. Assuming that blasting generates a blasting cavity with a width of $0.2 \mathrm{~m}$ and a blasting weakened area with a radius of $2 \mathrm{~m}$, a horizontal stress monitoring line is arranged along the midpoint of the coal seam height to record the change trend of the stress in the coal pillar, as shown in Figure 10.

As can be seen from Figure 10, the presplit blasting destroyed the rock mass around the blast hole, resulting in the formation of a plastic failure zone around the blast hole. The rock mass inside the area was loosely broken, the bearing capacity was weakened, and a local stress drop was observed. By comparing the stress curves at different presplitting locations, we can see that, when presplitting at $20 \mathrm{~m}$ ahead of the mining panel, the presplitting position is close to the stress peak area and the stress gradient is large, so the presplitting location is severely damaged under the action of dynamic load, and the stress drops by $3 \mathrm{MPa}$ compared to the case without presplitting at the same location. The range of the stress rise zone is reduced, and the entire advanced

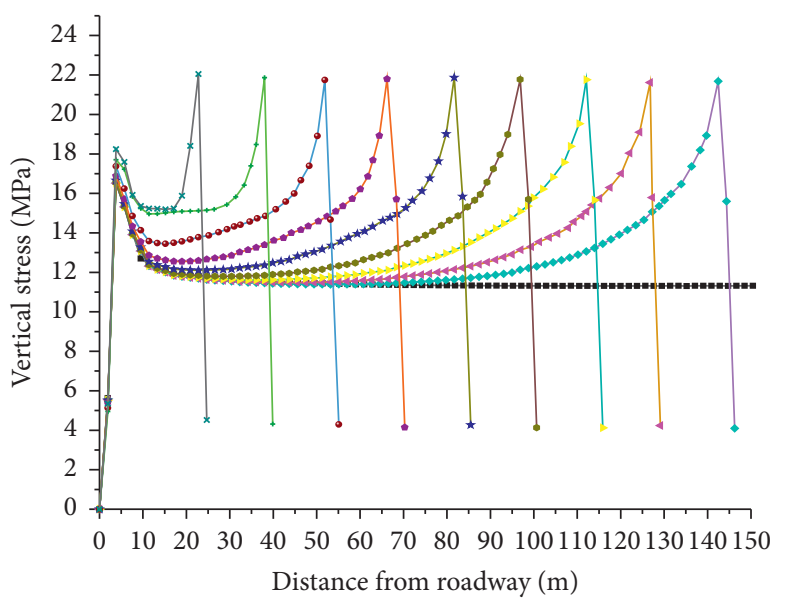

$$
\begin{aligned}
& \text { - Unmining } \quad \text { * } 85 \mathrm{~m} \text { coal pillar } \\
& \multimap-145 \mathrm{~m} \text { coal pillar } \rightarrow 70 \mathrm{~m} \text { coal pillar } \\
& \longleftarrow 130 \mathrm{~m} \text { coal pillar } \quad \rightarrow 55 \mathrm{~m} \text { coal pillar } \\
& \rightarrow-115 \mathrm{~m} \text { coal pillar } \quad+\quad 40 \mathrm{~m} \text { coal pillar } \\
& \rightarrow 100 \mathrm{~m} \text { coal pillar } \quad \times 25 \mathrm{~m} \text { coal pillar }
\end{aligned}
$$

FIGURE 9: Stress curve with different widths of the coal pillar.

bearing stress range is reduced from $85 \mathrm{~m}$ to $55 \mathrm{~m}$. The presplitting of the mining panel at $35 \mathrm{~m}$ showed the same characteristics, but the degree of stress reduction was only 1.7 $\mathrm{MPa}$, and the range of the advanced abutment stress was shortened to $70 \mathrm{~m}$. When the presplitted mining panel is $50 \mathrm{~m}$ and $65 \mathrm{~m}$, due to the balanced stress distribution on both sides of the presplitted position, only the stress reduction phenomenon is shown at the presplitted position, but the range of the advanced abutment stress is not reduced.

4.3.3. The Effect of Deep Hole Blasting on the Advanced Abutment Stress Field. The artificial cracks produced by the advanced deep hole blasting intersect with the original cracks, which makes the roof collapse with mining, weakening the source of the advanced abutment stress. Under the influence of mining stress, the roof in front of the coal wall is broken more and the bearing capacity is reduced. As shown in Figure 11, the peak stress is reduced from $22 \mathrm{MPa}$ to $18 \mathrm{MPa}$, and the area of increased stress shifts deeper. After the deep hole blasting, the stress concentration is reduced overall, and the stress change gradient is reduced. The presplitting position shows that the degree of stress blocking is weaker than that before. The field range was further reduced to $55 \mathrm{~m}$.

By arranging measuring points at $10 \mathrm{~m}$ on both sides of the presplitting zone and recording the speed-time curve of the measuring points, the propagation of stress waves in the roof and the blocking effect of cracks on dynamic loads were studied. Figure 12 shows the vibration time-history curves of the nodes in the horizontal and vertical directions of the top plate, respectively. As can be seen from Figure 12(a), the entire vibration time-history at the location of measuring point 1 lasts about $0.06 \mathrm{~s}$. The curve is triangular and consistent with the dynamic load of the analog input. The peak value is $53 \times 10-2 \mathrm{~cm} / \mathrm{s}$. With the increase of the propagation distance of the stress wave and 


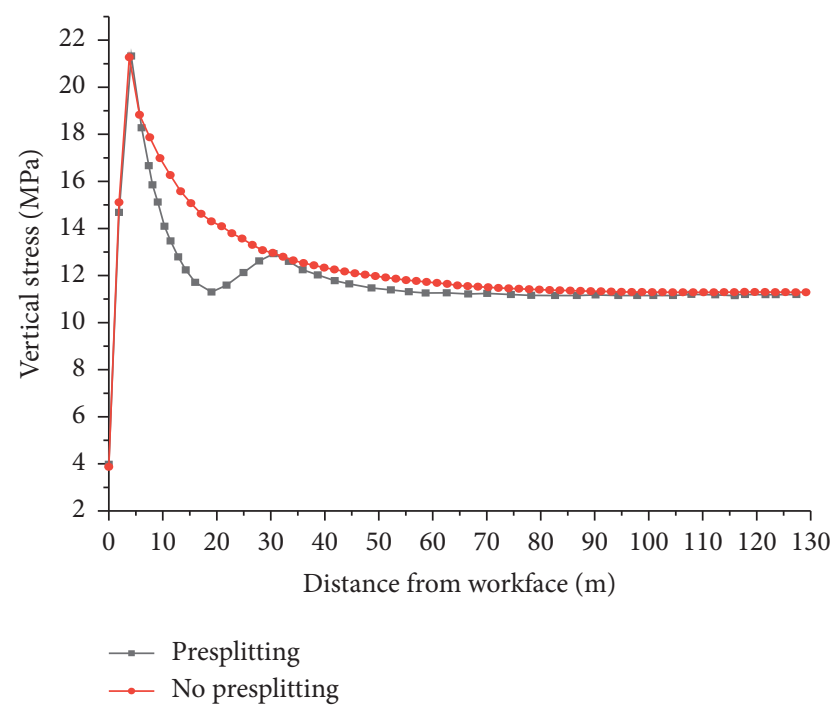

(a)

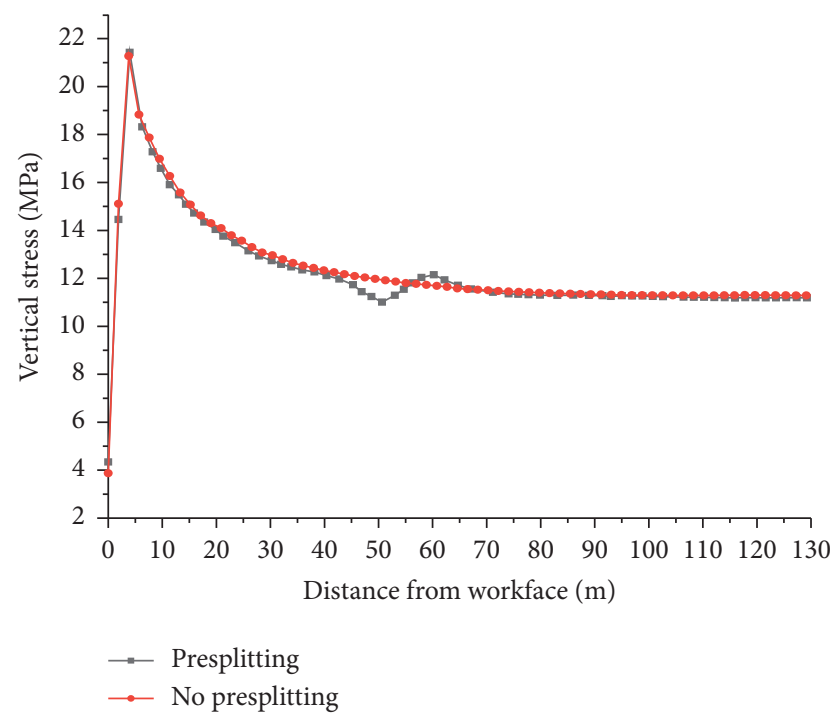

(c)

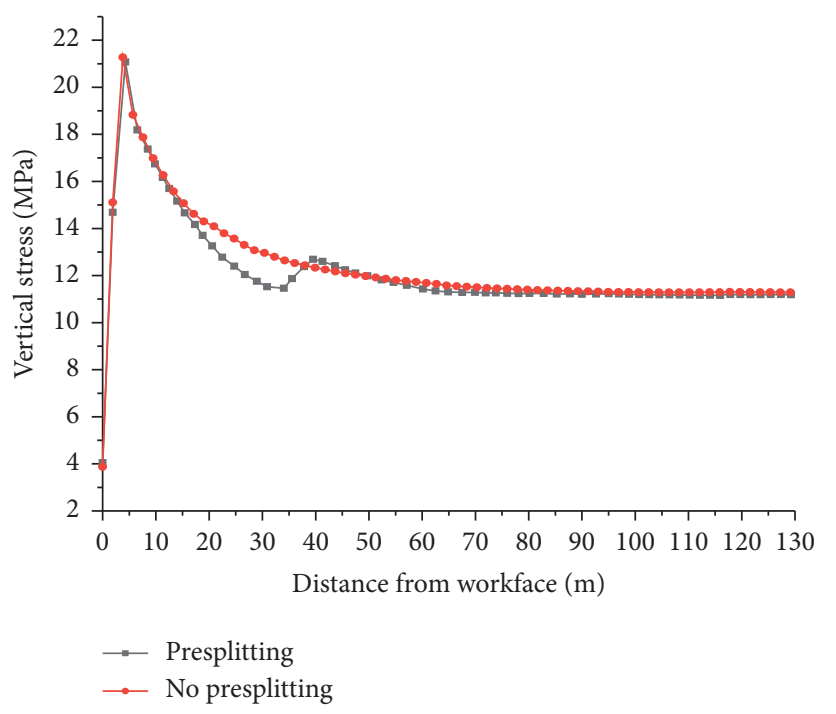

(b)

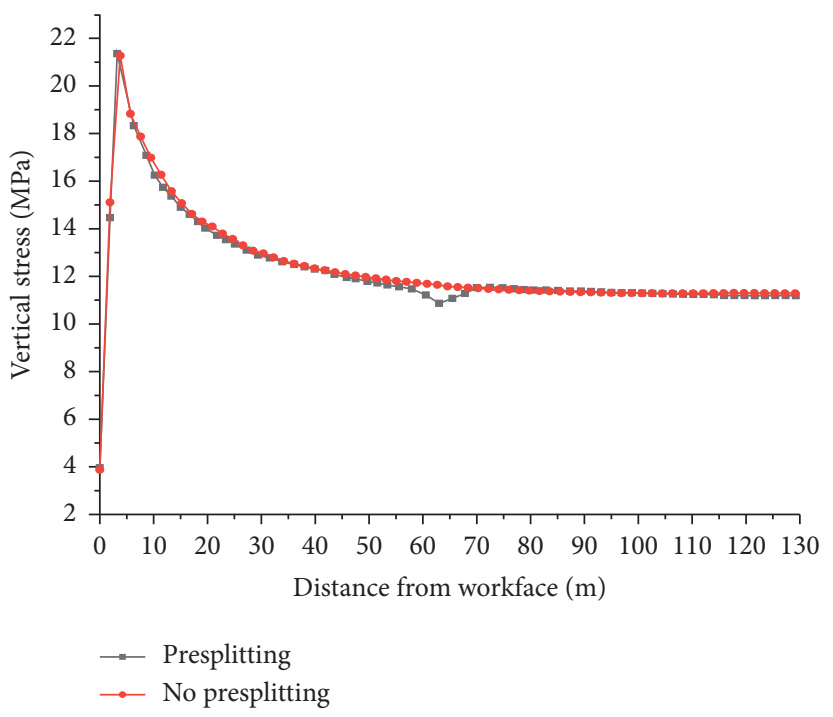

(d)

Figure 10: Vertical stress curves at different presplitting positions. (a) $20 \mathrm{~m}$ ahead mining panel. (b) $35 \mathrm{~m}$ ahead mining panel. (c) $50 \mathrm{~m}$ ahead mining panel. (d) $65 \mathrm{~m}$ ahead mining panel.

the existence of damping, the amplitude decreases to $38 \times 10^{-2} \mathrm{~cm} / \mathrm{s}$ at the presplitting zone, and transmission and reflection phenomena occur at the presplitted surface, because the distances between the measuring points 1 and 3 to the crack are the same. At about $0.2 \mathrm{~s}$, the vibration waveform was simultaneously monitored at measuring point 3 and measuring point 1 , and the amplitudes were attenuated to $17 \times 10^{-2} \mathrm{~cm} / \mathrm{s}$ and $14 \times 10^{-2} \mathrm{~cm} / \mathrm{s}$, respectively. The transmitted wave is attenuated by $68 \%$ compared to the incident wave. Although no dynamic load is applied in the direction perpendicular to the rock layer, due to the overall vibration of the rock layer and the reflection of the wave in the fissure, the vibration waveforms are monitored at measurement points 1 and 3 , and the amplitude of the waveform in the $y$ direction is much smaller than that in the $x$ direction. The crack surface cannot transmit the vibration in the $y$ direction, so the vibration waveform is not recorded at the monitoring point 2 . It can be seen that the crack has a significant blocking effect on the dynamic load.

\section{Field Application}

5.1. Project Overview. The 22115 mining panel of Shanxi Luning Coal Mine is close to the track dip, belt dip, and return dip. The depth is about $500 \mathrm{~m}$, the mining panel width is $207 \mathrm{~m}$, and the thickness of the coal seam in the minable section is $4.0 \mathrm{~m}$, and the inclination angle is $4^{\circ}$. The immediate roof is mudstone and siltstone with a thickness of $12 \mathrm{~m}$, and the main roof is fine-grained sandstone with a thickness of $8 \mathrm{~m}$. The hard roof is not easy to collapse, which leads to a large range of advanced abutment stress. It is easy to affect the stability of the surrounding rock when it is close to the roadway. As shown in Figure 13, in the past, when the $80 \mathrm{~m}$ 


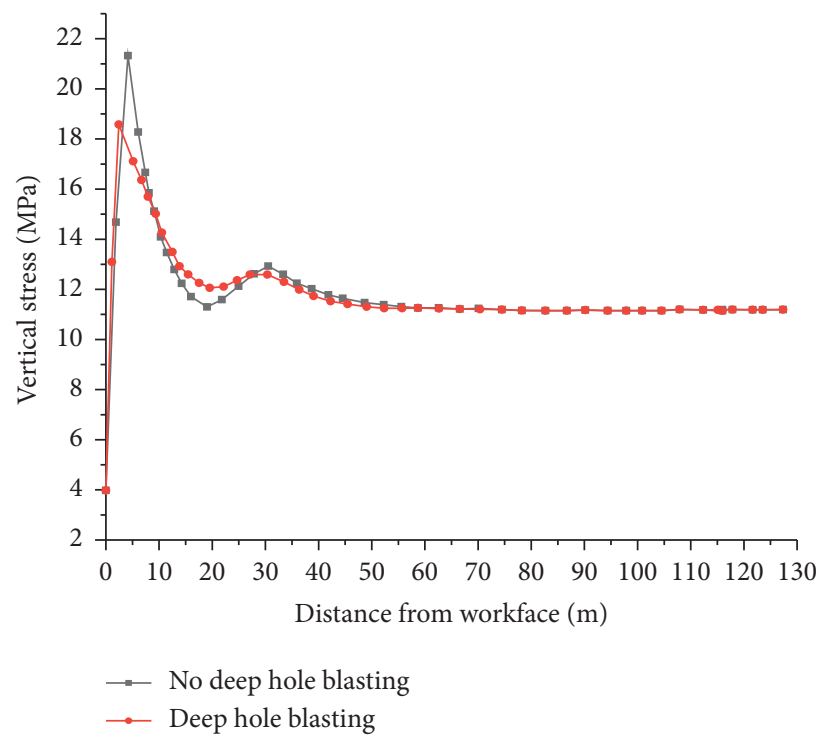

FIgURE 11: Vertical stress curves under deep hole blasting.

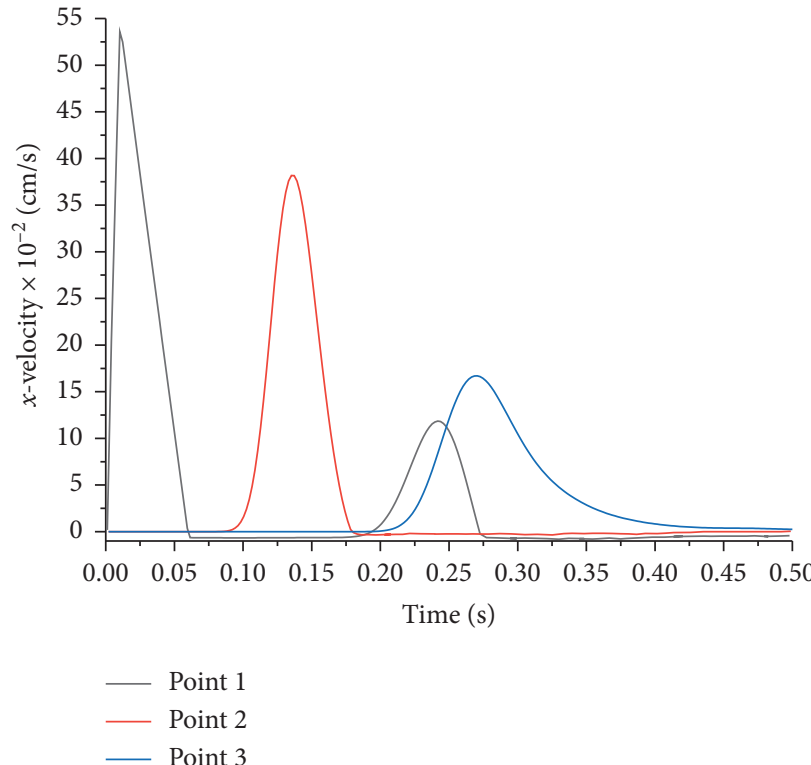

(a)

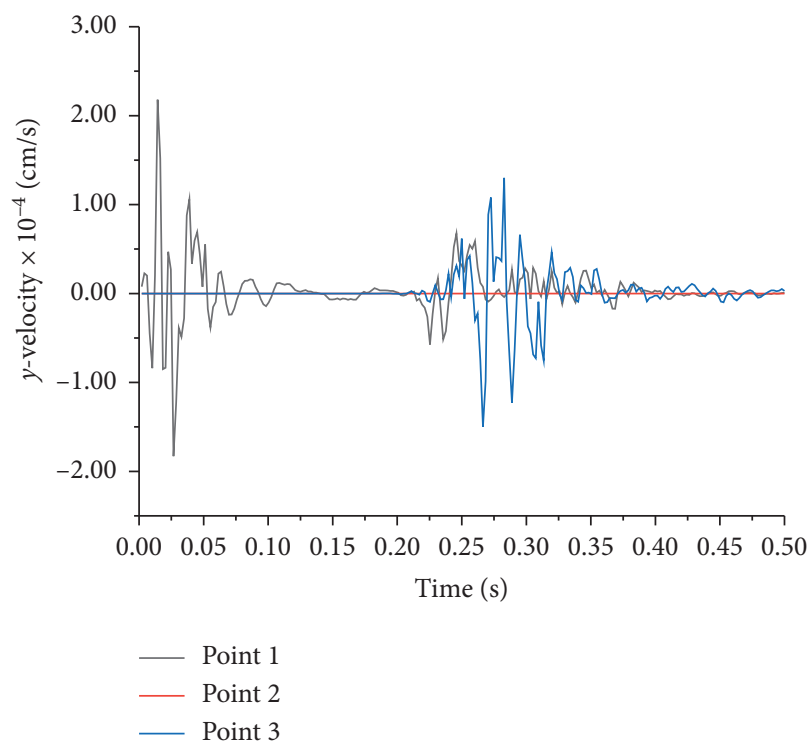

(b)

Figure 12: Speed-time curve of measuring point. (a) $x$-velocity. (b) $y$-velocity.

coal pillars were left, the surrounding rock of the roadway often had problems such as roofing and spalling rib. The roadway can only be protected by increasing the size of the coal pillar, resulting in a serious waste of coal resources.

5.2. Blasting Plan and Effect Monitoring. Through the combination of directional energy gathering blasting and advanced periodic deep hole blasting, the range of advanced abutment stress and the peak value of stress are reduced. The roof collapse is promoted to protect the safety of roadway and mining panel production. As shown in Figure 14, combined with the previous analysis, the end-mining coal pillar size is designed to be $60 \mathrm{~m}$, and firstly the directional presplit blasting is carried out $15 \mathrm{~m}$ in front of the end-mining line. Drilling obliquely upwards from the two roadways, the blast holes are distributed in a fan shape. Advanced periodic deep hole blasting is carried out during the normal mining of the mining panel, and every three blast holes are arranged in a group of fan-shaped ones. The blast hole parameters [21, 22] are designed according to the geological conditions of the working area and blasting requirements.

The monitoring mainly measures the advanced abutment stress. As shown in Figure 14, the measuring stations are respectively arranged on the both side of presplitting line, and each station is arranged with three measuring points. It 


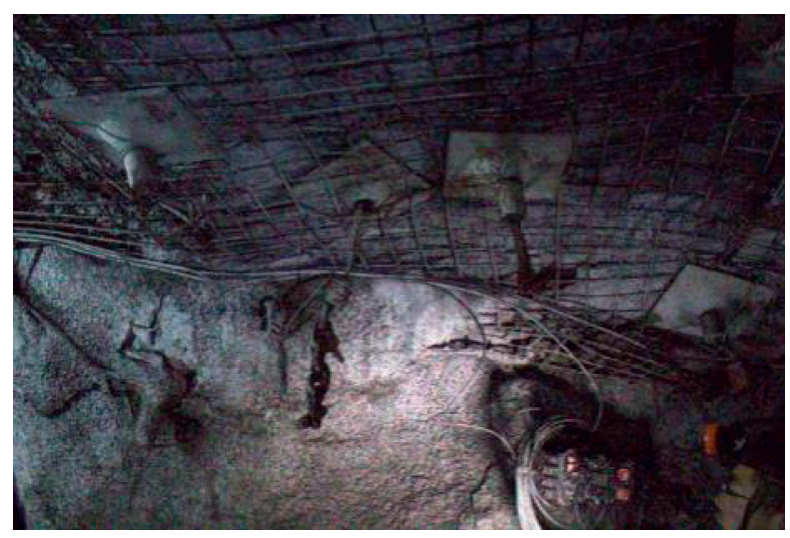

(a)

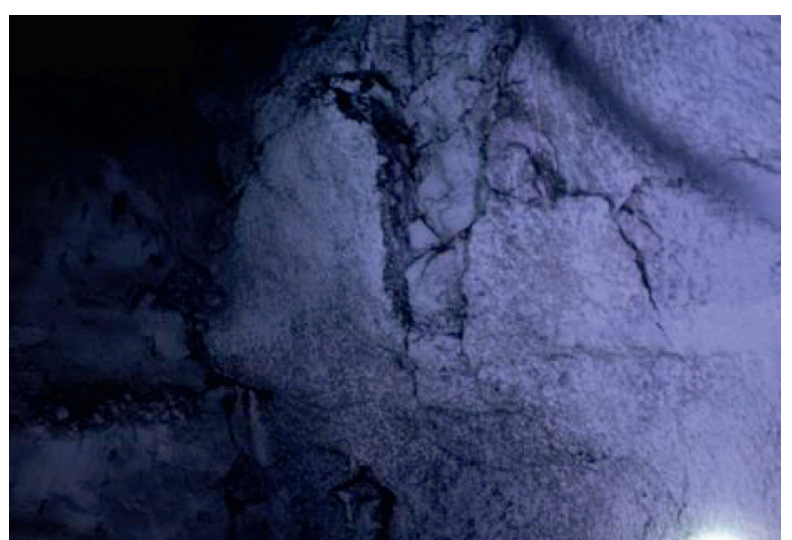

(b)

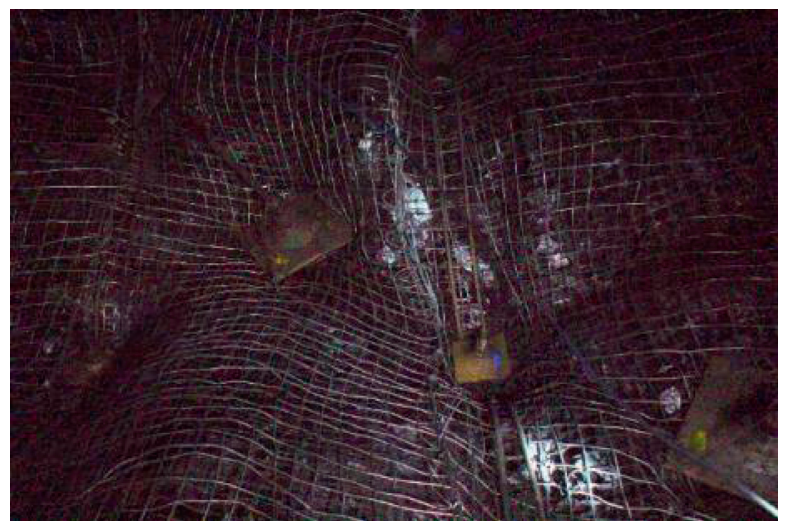

(c)

Figure 13: Roadway damage forms. (a) Roof collapse. (b) Spalling rib. (c) Anchor failure.

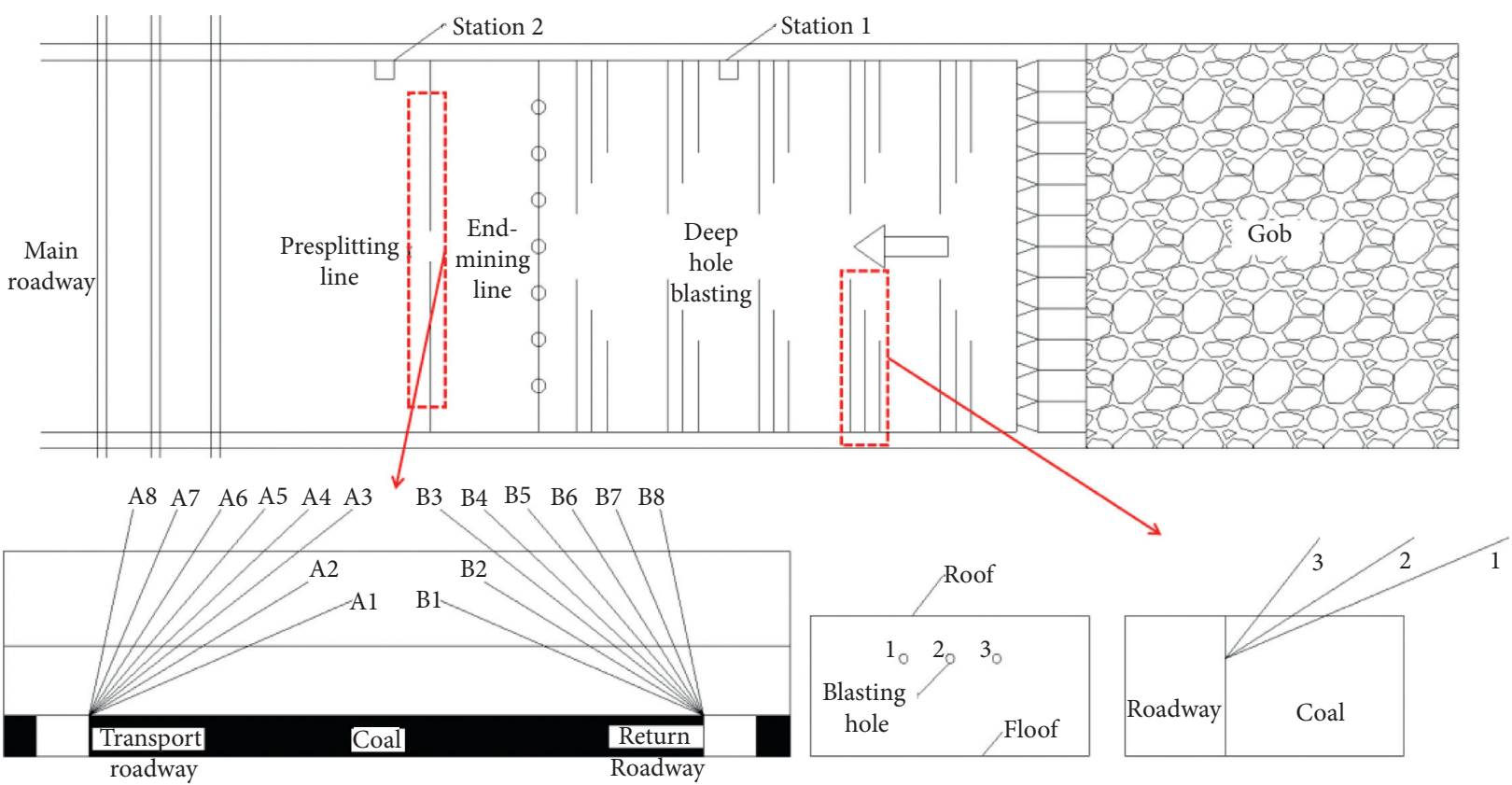

FIGURE 14: Blasting plan and blast hole layout. 


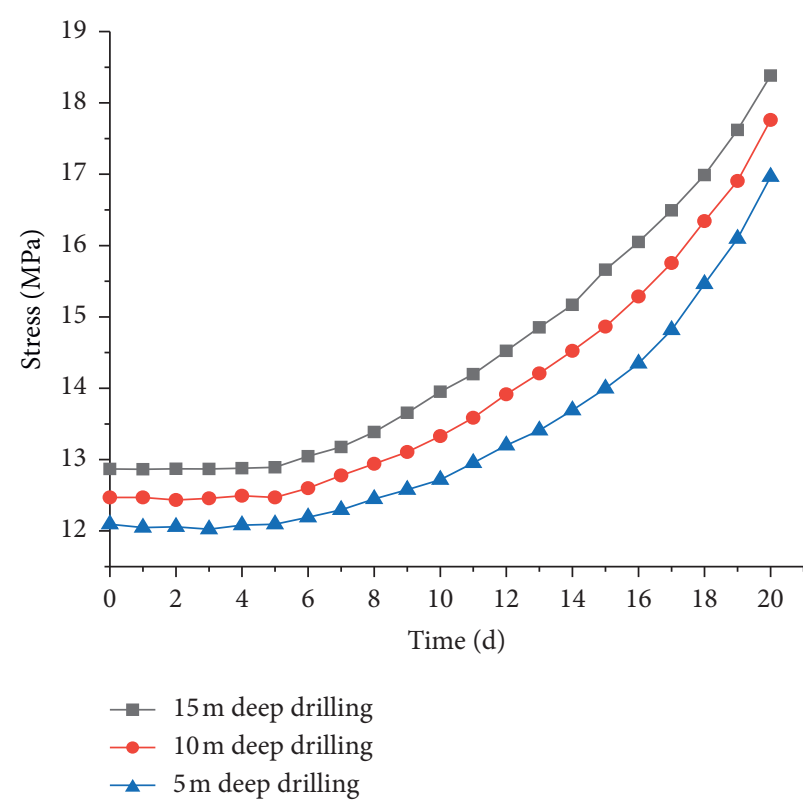

(a)

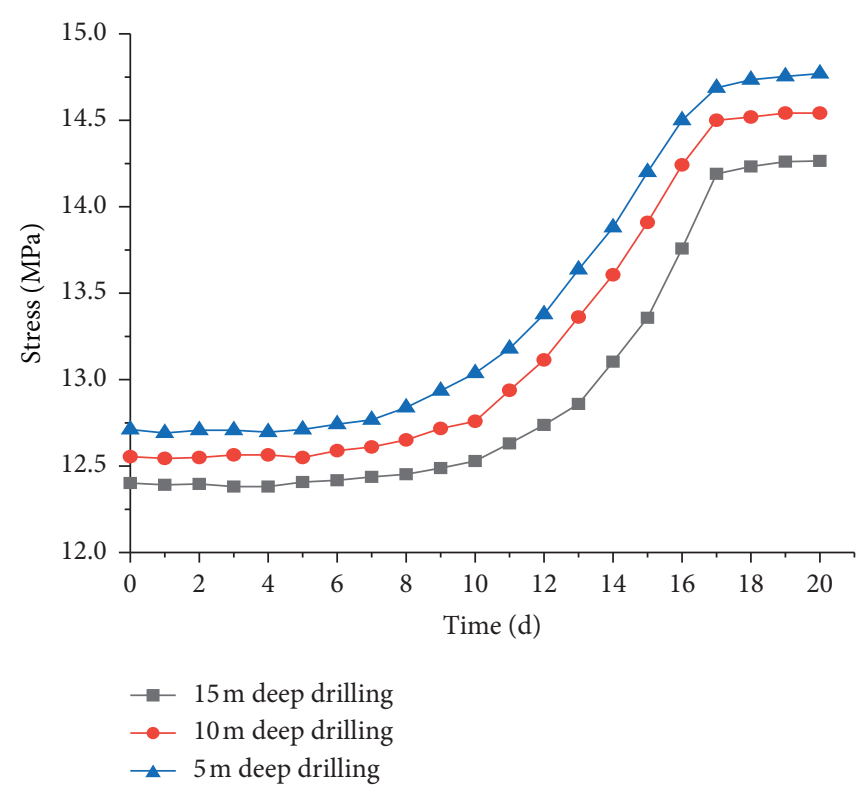

(b)

Figure 15: Abutment pressure monitoring curve. (a) Station 1. (b) Station 2.

can be seen from the monitoring result curve in Figure 15 that the number of days of stress increase of station 1 is about 16 days, and the value of station 2 remains unchanged after 9 days of pressure increase due to the stop of mining. Starting from the time point when the pressure count value began to increase, the stress value of station 1 increased by an average of $5 \mathrm{MPa}$, and the stress value of station 2 increased by an average of $2 \mathrm{MPa}$ within 9 days; the value of the advanced abutment stress decreased significantly. Calculated by considering the daily advance of mining $4 \mathrm{~m}$ and the layout of the station, after the blasting pressure relief technology was proposed in use, the advanced abutment stress range was reduced from $80 \mathrm{~m}$ to $55 \mathrm{~m}$.

\section{Conclusion}

This paper considers the problem that the width of the endmining coal pillar is large under hard roof conditions and the roadway is strongly affected by mining. Through the analysis of the distribution characteristics of the stress field inside the coal pillar, the calculation principle of the coal pillar size was obtained. Based on the formation conditions and transfer forms of the advanced abutment stress, a pressure relief technique using a combination of directional presplitting and deep hole blasting was proposed, and the pressure relief effect was studied through numerical simulation and field tests. The main conclusions are as follows:

(1) The size of the limit end-mining coal pillar is the sum of the range of the advanced abutment stress field and the stress field range of the roadway limit equilibrium area. When the stress disturbance boundary of the advanced abutment stress field overlaps with the boundary of the roadway stress field limit equilibrium zone, the surrounding rock gradually becomes unstable;

(2) The fracture surface formed by presplitting blasting leads to a decrease in the degree of rock layer connection, which can not only block the transmission of the static stress field in the stope but also cause attenuation of the dynamic load. Advanced deep hole blasting reduces the source of the advanced abutment stress by reducing the integrity of the roof and shortening the distance between one ceiling and the other ceiling;

(3) Numerical simulation analysis shows that the effect of presplitting blasting on stress is related to the gradient of the stress field. The closer the presplitting surface is to the peak of the advanced abutment stress, the more obvious the effect of stress blocking;

(4) The combination of presplitting blasting and deep hole blasting effectively controls the advanced abutment stress. The industrial test of 22115 mining panel shows that the surrounding rock of the downhill roadway remains stable even when the size of the end-mining coal pillar is shortened to $60 \mathrm{~m}$.

\section{Data Availability}

The data used to support the findings of this study are included within the article.

\section{Conflicts of Interest}

The authors declare that there are no conflicts of interest regarding the publication of this paper. 


\section{Acknowledgments}

This work was supported by the Fundamental Research Funds for the Central Universities (Grant no. 2019QNA19).

\section{References}

[1] N. Li, B. Huang, X. Zhang, T. Yuyang, and B. Li, "Characteristics of microseismic waveforms induced by hydraulic fracturing in coal seam for coal rock dynamic disasters prevention," Safety Science, vol. 115, pp. 188-198, 2019.

[2] D. Ma, H. Duan, W. Liu, X. Ma, and M. Tao, "Water-sediment two-phase flow inrush hazard in rock fractures of overburden strata during coal mining," Mine Water and the Environment, vol. 39, no. 2, pp. 308-319, 2020.

[3] A.-Y. Cao, L.-M. Dou, X. Luo, Y.-D. Zheng, J.-L. Huang, and K. Andrew, "Seismic effort of blasting wave transmitted in coal-rock mass associated with mining operation," Journal of Central South University, vol. 19, no. 9, pp. 2604-2610, 2012.

[4] Q. Zhang, E. Wang, X. Feng et al., "Rockburst risk analysis during high-hard roof breaking in deep mines," Natural Resources Research, vol. 29, no. 6, pp. 4085-4101, 2020.

[5] G. Wang, S. Gong, L. Dou, W. Cai, X. Yuan, and C. Fan, "Rockburst mechanism and control in coal seam with both syncline and hard strata," Safety Science, vol. 115, pp. 320-328, 2019.

[6] J. Xia, Y. Cheng, M. Zhao, C. Liu, and Y. Wen, "Study on mining technology of shallow hole + deep hole shrinkage method with ductule grouting in advance for roof reinforcement," IOP Conference Series: Earth and Environmental Science, vol. 295, Article ID 042123, 2019.

[7] J. Zuo, Z. Li, S. Zhao, Y. Jiang, H. Liu, and M. Yao, “A study of fractal deep-hole blasting and its induced stress behavior of hard roof strata in bayangaole coal mine, China," Advances in Civil Engineering, vol. 2019, Article ID 9504101, 14 pages, 2019.

[8] Z. Zhou, Y. Zhao, W. Cao, L. Chen, and J. Zhou, "Dynamic response of pillar workings induced by sudden pillar recovery," Rock Mechanics and Rock Engineering, vol. 51, no. 10, pp. 3075-3090, 2018.

[9] H. Liu, J. Dai, J. Jiang, P. Wang, and J. Yang, "Analysis of overburden structure and pressure-relief effect of hard roof blasting and cutting," Advances in Civil Engineering, vol. 2019, Article ID 1354652, 14 pages, 2019.

[10] Y. Chen, S. Ma, Y. Yang, N. Meng, and J. Bai, “Application of shallow-hole blasting in improving the stability of gob-side retaining entry in deep mines: a case study," Energies, vol. 12, no. 19, p. 3623, 2019.

[11] T. Hu, "Study on the parameters of roadside support after the cantilever beam of the basic roof with height of fracture zone cut by deep-hole blasting," IOP Conference Series: Earth and Environmental Science, vol. 283, Article ID 012038, 2019.

[12] B. Huang, J. Liu, and Q. Zhang, "The reasonable breaking location of overhanging hard roof for directional hydraulic fracturing to control strong strata behaviors of gob-side entry," International Journal of Rock Mechanics and Mining Sciences, vol. 103, pp. 1-11, 2018.

[13] J. Yang, C. Liu, and B. Yu, "Application of confined blasting in water-filled deep holes to control strong rock pressure in hard rock mines," Energies, vol. 10, no. 11, p. 1874, 2017.

[14] B. Chen, C. Liu, and J. Yang, "Design and application of blasting parameters for presplitting hard roof with the aid of empty-hole effect," Shock and Vibration, vol. 2018, Article ID 8749415, 16 pages, 2018.
[15] G. R. Feng, "Study on rational width of the end-mining coal pillar of extra-thick mining panel in permo-carboniferous igneous rock intrusion area," Journal of Mining \& Safety Engineering, vol. 36, no. 1, pp. 87-94, 2019, in Chinese.

[16] L. X. Xie, Q. B. Zhang, J. C. Gu et al., "Damage evolution mechanism in production blasting excavation under different stress fields," Simulation Modelling Practice and Theory, vol. 97, Article ID 101969, 2019.

[17] W. Yuan, S. Liu, W. Wang et al., "Numerical study on the fracturing mechanism of shock wave interactions between two adjacent blast holes in deep rock blasting," Earthquake Engineering and Engineering Vibration, vol. 18, no. 4, pp. 735-746, 2019.

[18] Z. Liu, A. Cao, G. Liu, and J. Li, "Experimental research on stress relief of high-stress coal based on noncoupling blasting," Arabian Journal for Science and Engineering, vol. 43, no. 7, pp. 3717-3724, 2018.

[19] X. Xu, M. He, C. Zhu, Y. Lin, and C. Cao, "A new calculation model of blasting damage degree-Based on fractal and tie rod damage theory," Engineering Fracture Mechanics, vol. 220, p. 106619, 2019.

[20] J. Hu, X. Zhang, Y. Gao, Z. Ma, X. Xu, and X. Zhang, "Directional presplit blasting in an innovative no-pillar mining approach," Journal of Geophysics and Engineering, vol. 16, no. 5, pp. 875-893, 2019.

[21] G. Yue et al., "Optimal layout of blasting holes in structural anisotropic coal seam," PLoS One, vol. 14, no. 6, Article ID e0218105, 2019.

[22] P. Bańka, H. Badura, and M. Wesołowski, “The possibility of increasing the efficiency of accessible coal deposits by optimizing dimensions of protective pillars or the scope of exploitation," IOP Conference Series: Materials Science and Engineering, vol. 268, Article ID 12005, 2017. 